\title{
Quantification of monosialogangliosides in human plasma through chemical derivatization for signal enhancement in LC-ESI-MS
}

Qianyang Huang ${ }^{\mathrm{a}}$, Danting Liu ${ }^{\mathrm{a}}$, Baozhong Xin ${ }^{\mathrm{c}}$, Karen Cechner ${ }^{\mathrm{c}}$,Xiang Zhou ${ }^{\mathrm{a}}$, Heng Wang $^{\mathrm{c}^{*}}$, and Aimin Zhou ${ }^{\mathrm{a}, \mathrm{b}^{*}}$

${ }^{\mathrm{a} C l i n i c a l}$ Chemistry Program, Department of Chemistry, ${ }^{\mathrm{b}}$ Center for Gene Regulation in Health and Diseases, Cleveland State University, 2121 Euclid Avenue, Cleveland, Ohio, 44115, United States

${ }^{\mathrm{c} D D C}$ Clinic, Center for Special Needs Children, 14567 Madison Road, Middlefield, Ohio, 44062, United States

\section{Running title: Quantification of monosialogangliosides in human plasma}

Keyword: Gangliosides, Mass spectrometry, Derivatization, Signal Enhancement, GM3 synthase deficiency, Neurological disorders

To whom correspondence should be addressed:

Dr. Aimin Zhou, Clinical Chemistry Program, Department of Chemistry, Cleveland State University, 2121 Euclid Avenue,SR397, Cleveland, OH 44115; Phone: 216-687-2416; Fax: 216-687-9298; e-mail: a.zhou@csuohio.edu

Dr. Heng Wang, DDC Clinic, Center for Special Needs Children, 14567 Madison Road, Middlefield, OH 44062; Phone: 440-632-1668; Fax: 440-632-1697; e-mail: Wang@ddcclinic.org. 


\section{Abstract}

Gangliosides are found in abundance in the central nervous system of vertebrates. Their metabolic disruption and dysfunction are associated with various neurodegenerative disorders such as Alzheimer's disease and Parkinson's disease. In order to improve our understanding of the etiology of these diseases, analytical ganglioside assays with sufficient specificity and sensitivity in relevant biological matrices are required. In the present work we have developed and validated a reverse-phase ultra-performance liquid chromatography (UPLC)/tandem mass spectrometry (MS) method for determining monosialogangliosides GM1, GM2, and GM3 present in human plasma. Compared with our previous method, this method enhanced, by 15 fold, MS responses of the analytes by employing 2-(2-Pyridilamino)-ethylamine (PAEA) \& 4-(4, 6-Dimethoxy-1, 3, 5-triazin-2-yl)-4-methylmorpholinium chloride (DMTMM)-based derivatization. The analytes and internal standards were derivatized with PAEA\&DMTMM after extraction from plasma using a protein precipitation procedure. They were then purified using liquid-liquid partitioning. When the samples were then analyzed by UPLC-MS/MS with a multiple reaction monitoring (MRM) mode, we achieved superior sensitivity and specificity. This method was evaluated for extraction recovery, calibration linearity, precision, accuracy, and lower limit of quantification (LLOQ). The validated method was successfully applied to monitor monosialoganglioside levels in the plasma from patients with GM3 synthase deficiency. With significantly increased sensitivity, we have, for the first time, detected a significant amount of GM3 
in the affected patients.

\section{Introduction}

Gangliosides are a large subfamily of glycosphingolipids that are abundant in the central nervous system of vertebrates [1]. Except for the presence of sialic acid residues, they are similar to other glycosphingolipid species, as they possess hydrophilic carbohydrate moieties attached to ceramide backbones (shown in Fig.1). Gangliosides are generally classified and named according to the degree of sialylation and the monosaccharide makeup of the carbohydrate moieties. In addition to the diversity of their carbohydrate moieties, the presence of long alkyl chain fatty acids with variable chain length and saturation degree in the ceramide portion generates an extra degree of heterogeneity of their structures [2], thus, explaining their physiological versatility in regulation of the central nervous system of living organisms.

Gangliosides have been found to be ubiquitous components which are predominantly localized on the outer leaflet of the plasma membrane along with other integral membrane components, such as trans-membrane proteins, sphingomyelins, and cholesterols. These components form characteristic regions known as glycolipid-enriched microdomains or lipid rafts on the mammalian cell membrane, which play a fundamental role in maintenance and organization of the integration and dynamic behavior of the membrane lipid bilayer scaffold [3]. Moreover, gangliosides are involved in cell proliferation, differentiation, migration, and adhesion by functional interaction with the extracellular domain of receptors, including epidermal 
growth factor receptor (EGFR) [4], platelet-derived growth factor receptor [5-8], fibroblast growth factor receptor [9], Trk receptor [10-12], and insulin receptors [13]. Disruption of gangliosides has been found to contribute to the pathogenesis of certain tyrosine kinase receptor-mediated disorders [14].

Genetic defects in the ganglioside biosynthesis pathway may be devastating. GM3 synthase deficiency (GSD) is a newly identified neurological disorder that has been prevalently found in the Amish population in the United States [15-17]. Although the pathological mechanism remains to be understood, the condition is severe. It is characterized by infantile onset of severe irritability, failure to thrive, developmental stagnation, cortical blindness, profound intellectual disability and intractable seizures. In addition, mounting evidence has illustrated that the abnormal ganglioside profile is implicated in the development of various neurodegenerative syndromes, such as Parkinson's disease [18-19] and Alzheimer's disease [20].

A variety of assays have been developed for the measurement or profiling of different gangliosides in animal tissues, culture cells, and cerebrospinal fluid using thin layer chromatography interfaced with densitometric [21] or immunochemical detection [22], high performance liquid chromatography (HPLC) [23-24], supercritical fluid chromatography [25], and enzyme-linked immune-sorbent assay [26]. However, these methods are, in general, limited by large sample requirements, laborious sample preparation, and poor assay sensitivity. The technological advancement of mass spectrometry interfaced with the HPLC system with electrospray ionization (ESI) source technology has given rise to greater specificity and sensitivity of ganglioside 
assays from biological matrices. Previously, Gu et al. established a method for simultaneous quantification of GM1 and GM2 gangliosides in human cerebrospinal fluid using reverse phase LC/MS [27]. Sorensen et al. reported a liquid chromatographic approach with tandem mass spectrometry for the quantification of gangliosides GD3 and GM3 in bovine milk and infant formula [28].

Recently, we developed a reverse-phase UPLC-MS/MS method for the determination of gangliosides GM2, GM3, GD2, and GD3 in human plasma [29]. This method has been applied to monitor the levels of these gangliosides in plasma samples from patients with GSD. However, insufficient sensitivity of this method has been one of the major obstacles in measuring the plasma levels of monosialogangliosides in patients with GSD. In the present work, we have developed and validated a new UPLC-MS/MS method with enhanced sensitivity for the measurement of three monosialoganglioside species (GM1, GM2, and GM3) in human plasma using PAEA\&DMTMM-based derivatization. This method employed reverse phase UPLC for chromatographic separation and tandem mass spectrometry in the MRM mode for enhanced detection, sensitivity, and specificity. The ESI-MS responses of the three monosialogangliosides were enhanced over 15 fold following PAEA\&DMTMM-based derivatization. We have successfully applied this method to the determination of monosialoganglioside levels in human plasma from GSD patients, carriers and normal adults.

\section{Experimental}




\subsection{Materials}

Derivatization reagents4-(4,6-Dimethoxy-1,3,5-triazin-2-yl)-4-methylmorpholinium chloride (DMTMM) and 2-(2-Pyridilamino)ethylamine (PAEA) were purchased from Sigma Aldrich (St. Louis, MO) and Santa Cruz (Dallas, TX), respectively. Calibration standards GM1, GM2, and GM3 were obtained from EMD Chemicals (Billerica, MA) and Avanti lipids (Alabaster, AL). Internal standards N-omega-CD3-Octadecanoyl monosialogangliosidesGM1 $\quad\left({ }^{2} \mathrm{D}_{3}-\mathrm{GM} 1\right), \quad \mathrm{GM} 2$ ( $\left.{ }^{2} \mathrm{D}_{3}-\mathrm{GM} 1\right)$, and GM3 ( $\left.{ }^{2} \mathrm{D}_{3}-\mathrm{GM} 3\right)$ were purchased from Matreya LLC (Pleasant Gap, PA). HPLC grade methanol, acetonitrile, and isopropanol were obtained from EMD Milipore (Billerica, MA). HPLC grade formic acid was obtained from Fisher Scientific (Pittsburgh, PA). Deionized water was prepared using the Barnstead Nano-PURE Water Purification System (Asheville, NC). All materials were used directly without further purification.

\subsection{Human Plasma}

The study was approved by the DDC Clinic Institutional Review Board, and written informed consent was obtained from the study subjects or their legal guardians. The genotypes of the studied patients were determined through DNA sequencing and mutation analysis. The human plasma samples were stored at $-20^{\circ} \mathrm{C}$ before analysis.

\subsection{Stock and Working Solutions}


Stock solutions of DMTMM and PAEA were prepared by dissolving the lyophilized powders in 1:1 MeOH/Isopropanol to obtain concentrations of $1 \mathrm{M}$, and their working solutions with concentrations of $100 \mathrm{mM}$ were obtained by serial dilution with 1:1 $\mathrm{MeOH} /$ Isopropanol.

Stock solutions of GM1, GM2, and GM3 were prepared by dissolving the lyophilized powders in $90 \% \mathrm{MeOH}$ to obtain equal concentrations of $0.250 \mathrm{mg} / \mathrm{mL}$. The seven-level working solutions, which also served as calibrators, were prepared though serial dilution with $90 \% \mathrm{MeOH}$ to obtain concentrations of $10.0,20.0,50.0,1.00 \times 10^{2}$, $4.00 \times 10^{2}, 1.00 \times 10^{3}, 2.00 \times 10^{3} \mathrm{ng} / \mathrm{mL}$ for GM1, $10.0,20.0,50.0,1.00 \times 10^{2}, 4.00 \times 10^{2}$, $1.00 \times 10^{3}, 2.00 \times 10^{3} \mathrm{ng} / \mathrm{mL}$ for GM2, and $80.0,1.60 \times 10^{2}, 4.00 \times 10^{2}, 8.00 \times 10^{2}$, $3.20 \times 10^{3}, 8.00 \times 10^{3}, 1.60 \times 10^{4} \mathrm{ng} / \mathrm{mL}$ for GM3. The preparation of three-level QC working solutions was carried out in a similar manner to obtain concentrations of 25.0, $2.50 \times 10^{2}, 1.60 \times 10^{3} \mathrm{ng} / \mathrm{mL}$ for GM1, 25.0, $2.50 \times 10^{2}, 1.60 \times 10^{3} \mathrm{ng} / \mathrm{mL}$ for GM2, and $2.00 \times 10^{2}, 2 \times 10^{3}, 1.28 \times 10^{4} \mathrm{ng} / \mathrm{mL}$ for GM3. Likewise, stock solutions of ISs ${ }^{2} \mathrm{D}_{3}$-GM1, ${ }^{2} \mathrm{D}_{3}-\mathrm{GM} 1$, and ${ }^{2} \mathrm{D}_{3}-\mathrm{GM} 3$ were prepared by dissolving the lyophilized powders in $90 \% \mathrm{MeOH}$ to obtain concentrations of $0.250 \mathrm{mg} / \mathrm{mL}$. The IS working solution was prepared by dilution of the corresponding stock solution in $90 \% \mathrm{MeOH}$ to provide a concentration of $5.00 \times 10^{2} \mathrm{ng} / \mathrm{mL}$ for each IS.

The low plasma QC working solution was prepared by pooling plasma samples from multiple GSD patients and dividing the pool into $20 \mu \mathrm{L}$ aliquots. The high plasma QC working solution was prepared by pooling plasma samples from normal adults and dividing the pool into $20 \mu \mathrm{L}$ aliquots. 
All prepared stock and working solutions were kept at $-20^{\circ} \mathrm{C}$ before use.

\subsection{Sample Preparation}

Working plasma samples were prepared with $20 \mu \mathrm{L}$ of plasma and $10 \mu \mathrm{L}$ of IS working solution. The prepared samples were subjected to the sample extraction phase described below.

For calibration, each calibrator was prepared by mixing $10 \mu \mathrm{L}$ of a corresponding calibrator working solution with $10 \mu \mathrm{L}$ IS working solution. The calibrators were then subjected to the sample derivatization phase described below.

During the sample extraction phase, the prepared plasma samples underwent protein precipitation with the addition of $190 \mu \mathrm{L}$ of methanol as described previously [29]. The supernatant was transferred into a $1.7-\mathrm{mL}$ plastic centrifuge vial for subsequent extraction. Thereafter, $200 \mu \mathrm{L}$ of water and $160 \mu \mathrm{L}$ of chloroform were added to the supernatant. After vortexing, the mixture was centrifuged at $10,000 \mathrm{~g}$ for $3 \mathrm{~min}$ to separate the liquid into two phases. The upper phase was transferred into a new 1.7-mL centrifuge vial. A similar extraction was repeated twice for the lower phase with $200 \mu \mathrm{L}$ of $\mathrm{MeOH}$ and $200 \mu \mathrm{L}$ of water for each trial. The extracts were combined and subjected to the derivatization phase.

During the sample derivatization phase, each sample (plasma extract/calibrator) was dried under a continuous nitrogen stream, and reconstituted with $40 \mu \mathrm{L}$ of isopropanol. Thereafter, 12 and $48 \mu \mathrm{L}$ of PAEA and DMTMM working solutions respectively were added into the reconstituted samples. The reaction mixture was vortexed to mix thoroughly, and incubated at $80^{\circ} \mathrm{C}$ on a heat block for $40 \mathrm{~min}$. After the incubation, the 
sample vial was removed and placed in an ice bath to terminate the reaction. Once cooled, $100 \mu \mathrm{L}$ of isopropanol was added to dilute the mixture to a total volume of $200 \mu \mathrm{L}$. Following vortexing, the mixture was centrifuged at 5,000g for $1 \mathrm{~min}$ and the supernatant was transferred into an auto-sampler vial with a micro-insert for LC/MS analysis.

\subsection{LC/MS Instrumentation}

The UPLC system was composed of a DGU-20A 3 R degasser, two LC-30AD pumps, a SIL-30AC autosampler, a CTO-10A column oven and a CBM-20A system controller from Shimadzu (Columbia, MD). The UPLC system was interfaced with a Qtrap 5500 mass spectrometer equipped with an electrospray ionization source and a built-in Valco switch valve from AB SCIEX (Framingham, MA). The Multiple Reaction Monitoring (MRM) mode was utilized for quantitation. Individual MRM transitions are given in Table 1. Data acquisition and chromatographic peak integration were conducted using the Analysis 1.6.1 software package from AB SCIEX.

\subsection{LC-MS/MS Procedure}

Following chemical derivatization, $10 \mu \mathrm{L}$ of the sample was injected onto a Kinetex-C8 UPLC column $(1.7 \mu \mathrm{m}, 50 \mathrm{~mm} \times 2.1 \mathrm{~mm}$; Phenomenex, Torrance, CA) guarded with a C8 Security Cartridge. The mobile phase consisted of a mixture of $2 \%$ $\mathrm{MeOH}$ with $1 \%$ formic acid (A) and $\mathrm{ACN}-\mathrm{MeOH}(6: 4)$ with $1 \%$ formic acid (B). Chromatographic separation was implemented employing a gradient elusion program. 
Briefly, the initial B\% was maintained at $50 \%$ for 1 min and steeply increased to $75 \%$ at $1.5 \mathrm{~min}$ followed by a linear increase to $95 \%$ at $7 \mathrm{~min}$. Thereafter, the $\mathrm{B} \%$ was held constant at $95 \%$ for an additional 1.5 min and then dropped immediately to $50 \%$ for the remainder of the run. In addition, the $\mathrm{LC}$ eluent at $0.3 \mathrm{~mL} / \mathrm{min}$ was directed into the waste during the first 4.5 minutes and then introduced into the electrospray ionization source from 4.6 to 8.0 minutes, as all derivatized monosialoganglioside components were sequentially eluted and detected. Thereafter, the flow rate was increased to $0.6 \mathrm{~mL} / \mathrm{min}$ to rapidly clean and re-equilibrate the column for the next run. The temperatures of the auto-sampler and column oven were maintained at $4{ }^{\circ} \mathrm{C}$ and $35^{\circ} \mathrm{C}$ respectively throughout the analysis.

\subsection{Calibration Curve}

Ganglioside quantitation of the plasma samples was conducted using calibration curves based on seven levels. For each of the three monosialoganglioside species, the total peak area was calculated by summing up the IS-normalized peak areas of individual components based on a single injection.

The seven-level calibration curves were then established by plotting the IS-normalized total peak area of each measured monosialoganglioside species on the $y$-axis against concentration levels of the seven-level calibrators on the x-axis. A linear regression with a weighting factor of $1 / y^{2}$ was employed. The calculated equation was applied to the measurement of monosialoganglioside levels in each plasma sample. The standard calibration curves for measured monosialoganglioside 
species are shown in Fig. 2.

\section{Results and Discussion}

\subsection{Derivatization Conditions}

Since the carboxylic acid group on the sialic acid residue has a high preference to lose a proton, negative ESI is a more common option in generating singly charged molecular ions of monosialogangliosides than positive ESI in terms of ionization efficiency. However, because of their high molecular weight, the $\mathrm{m} / \mathrm{z}$ values of singly charged molecular ions of major monosialoganglioside species are virtually beyond the detection range of many commercially available triple-quadrupole mass spectrometers, including our instrument. Therefore, the selection of corresponding doubly charged molecular ions with detectable $\mathrm{m} / \mathrm{z}$ values has been a more practical approach to analysis of these molecules with the instruments. Based on our preliminary studies, the absence of an additional proton donating/accepting group on native structures of monosialogangliosides impedes the dual proton transferring pathway during ionization. This effect accounts for the low tendency of accepting/donating two protons by monosialogangliosides in ESI and the insufficient generation of doubly charged molecular ions in their MS profile, resulting in limited detection sensitivity. In order to overcome the limitation, modifications of their native structures are needed to increase the efficiency of generation of corresponding doubly charged molecular ions in ESI.

The PAEA\&DMTMM-based derivatization was first reported by Shin-ichi Endo et al. 
[30] for signal enhancement in the analysis of sialic acid Neu5Ac and ganglioside GM3 using MALDI-TOF-MS. In addition, the PAEA-GM3 exhibited significantly greater reinforcement of MS response. However, it was discovered that the derivatization yields of GM1, GM2, and GM3 were extremely poor under the reported conditions. In order to overcome this limitation, we optimized reaction conditions in terms of reagent concentration, reaction time, reaction temperature, reaction solvent, as well as instrumental conditions in order to achieve a maximal LC/MS peak area from the analytes. In this study, we found that $12 \mathrm{mM}$ PAEA and $48 \mathrm{mM}$ DMTMM provided the maximal LC peak area for all measured monosialoganglioside species. In addition, $80^{\circ} \mathrm{C} / 40 \mathrm{~min}$ was found to be the most favorable temperature/time for the reaction. Under the optimized conditions, the reaction yield was observed to be above $90 \%$. With this derivatization, we observed greater than 15 -fold signal enhancement compared with the previously reported method [29]. Due to the abundance of doubly charged molecular ions in positive ESI. This beneficial effect could be attributed to the addition of a pyridylamine group, a preferable dual-proton acceptor. The reaction mechanism is elaborated in Fig. 3.

\subsection{Mass Spectrometric Conditions}

The representative product ion mass spectra of d18:1-20:0 components for GM1, GM2, and GM3are shown in Fig. 4. As illustrated by their MS/MS profiles, monosialogangliosides appeared to share similarities in their fragmentation patterns, including common fragments $\mathrm{m} / \mathrm{z}=411.2$ and 573.2 , corresponding to fragments 
$[\mathrm{PAEA}-\mathrm{Neu} 5 \mathrm{Ac}+\mathrm{H}]^{+}$and $[\mathrm{PAEA}-\mathrm{Neu} 5 \mathrm{Ac}-\mathrm{Gla}+\mathrm{H}]^{+}$, respectively. This confirms that the desired position has been preferentially derivatized. In addition, the universal fragment $\mathrm{m} / \mathrm{z}=411.2$ was observed to be most abundant among any other fragments present in the MS/MS profiles of PAEA-monosialogangliosides.

After evaluating the quality of different possible precursor $\rightarrow$ daughter ion pairs for quantitation, we found that the following MRM transitions provided the optimal quantitative performance in terms of detection sensitivity and specificity: $[\mathrm{PAEA}-\mathrm{GM} 1+2 \mathrm{H}]^{2+} \rightarrow 411.2$ for GM1, $[\mathrm{PAEA}-\mathrm{GM} 2+2 \mathrm{H}]^{2+} \rightarrow 411.2$ for GM2, and $[\mathrm{PAEA}-\mathrm{GM} 3+2 \mathrm{H}]^{2+} \rightarrow 411.2$ for GM3. Moreover, transitions $[\mathrm{PAEA}-\mathrm{GM} 1+2 \mathrm{H}]^{2+} \rightarrow$ 573.2, $[\mathrm{PAEA}-\mathrm{GM} 2+2 \mathrm{H}]^{2+} \rightarrow 573.2$, and $[\mathrm{PAEA}-\mathrm{GM} 3+2 \mathrm{H}]^{2+} \rightarrow 573.2$ were also monitored for quality assurance. The monitored MRM transitions for quantitation are listed in Table 1. The fragmentation mechanisms for GM1, GM2, and GM3 are interpreted and elaborated in Fig. 5.

In addition, since sialic acid residues are well known to be fragile during electrospray ionization, in-source loss of sialic acid residues has been the primary concern associated with the analysis of sialic acid-containing molecules employing ESI-MS. Therefore, in order to determine the degree of in-source sialic acid loss during ESI, we carried out a series of experiments by individually injecting the derivatized standards into the LC and implementing MS full scan on Q3 under our experimental conditions. Based on the MS spectra we obtained at the retention times of our analytes (data not shown), the amount of PAEA-monosialogangliosides that underwent in-source loss was found to be insignificant during the ionization process. 


\subsection{HPLC Conditions}

Due to the chemical complexity of monosialoganglioside species, an appropriate chromatographic separation with one component being resolved and separated from another is essential to avoid the competition for ionization between co-eluates and to eliminate potential ionization suppression from matrix interferences during analysis. Based on our preliminary study, the analytes generally showed good resolution on separation but appeared to be overwhelmingly retentive on the C18 stationary phase. This was probably due to their elevated hydrophobicity after derivatization, which not only widened the chromatographic peak of individual components, but also prolonged the analysis time. In comparison, the C8 stationary phase with lower hydrophobicity was observed to retain the analytes less vigorously, enabling sharper chromatographic peaks and a shorter LC run time without sacrificing the separation resolution. The addition of acetonitrile to mobile phase B significantly reduced retention of the analytes on the $\mathrm{C} 8$ stationary phase and effectively shortened the chromatographic run in comparison with methanol only, leading to better peak shape and faster analysis. On the other hand, some methanol was necessary to maintain solubility of the analytes in the mobile phase during analysis. Therefore, the ratio of acetonitrile to methanol was optimized at 6 to 4 for the best chromatographic performance. Under our optimized LC conditions, different monosialoganglioside components were spread in a chromatographic window from 4.5 to $8 \mathrm{~min}$.

It is worth noting that the addition of $1 \%$ formic acid into the mobile phase 
substantially enhanced the peak intensities from all MRM transitions by many fold in positive ESI. This experimental phenomenon could be reasonably explained by the increased proton donating capability of the mobile phase upon the introduction of formic acid, allowing the dual-proton acceptance of PAEA-monosialogangliosideto be achieved at an elevated level in positive ESI. Expectedly, the reinforcement in MS response was observed to be less significant by the addition of ammonium formate and ammonium acetate in comparison with formic acid. This was due to their inability to lower the $\mathrm{pH}$ of the mobile phase which could be achieved with formic acid.

The addition of $1 \%$ formic acid into the mobile phase considerably reduced the buildup of derivatizing reagents on the column solid phase. This was due to enhanced ionization of leftover DMTMM\&PAEA, thereby decreasing their retention on the stationary phase, resulting in consistency and reproducibility of separation performance from the column over time.

\subsection{Method Validation}

\subsubsection{LLOQ, Precision and Accuracy}

The LLOQ, defined as S/N near or above 10, for each analyte was determined by analyzing samples prepared from 5 individual lots of plasma with the addition of their corresponding deuterium-labeled siblings. The LLOQs were 10,10 , and $80 \mathrm{ng} / \mathrm{mL}$ for GM1, GM2, and GM3, respectively, demonstrating the specificity and sensitivity of this assay for the accurate determination of monosialogangliosides in human plasma. The precision and accuracy for intra-assay and inter-assay measurements were assessed by analyzing QC standards prepared at three different concentrations in five 
replicates. As shown in Table 2, the coefficient of variation (CV \%) and relative error (RE \%) for intra- and inter-assay measurements were within $9 \%$ and $11 \%$, respectively. In addition, the precision for intra-assay and inter-assay measurements in the plasma matrix was also evaluated by analyzing samples prepared from five individual lots of high and low plasma QCs from unaffected adults and GSD patients on a single day and five different days, respectively. From the study, the CV\% from both high and low plasma QC measurements was found to be below 15\% as required by the FDA guidelines for bioanalytical method validation [31].

\subsubsection{Stability and Extraction Recovery}

Since stability of gangliosides in plasma under various storage conditions has already been evaluated during our previous studies [29], only the autosampler storage stability of PAEA-monosialogangliosides was evaluated in this study by analysis of the samples prepared from five individual lots of plasma from GSD patients with the addition of deuterium-labeled standards at QC concentrations before and after overnight storage at $4^{\circ} \mathrm{C}$. The stability values for the three monosialogangliosides were about $100 \%$ under these conditions as shown in Table 3, indicating no significant loss of any analytes under the storage conditions of the autosampler.

The extraction recoveries for all monosialogangliosides were assessed by comparably analyzing samples prepared from five individual lots of plasma from GSD patients with the addition of deuterium-labeled standards at QC concentrations in both preand post-extraction stages. As shown in Table 3, about $80 \sim 100 \%$ of analytes were 
recovered from the plasma matrix at the studied concentrations, indicating the effectiveness of our optimized sample extraction procedure.

\subsection{Method Application}

In this study, the validated method was successfully applied to measure the levels of monosialogangliosides in plasma samples from different specimens, including unaffected adults, GSD heterozygous carriers, and GSD patients, during the ongoing clinical study. As shown in Table 4, the plasma levels of monosialogangliosides from 31 normal adults were $(1.35 \pm 0.39) \times 10^{3},(4.71 \pm 1.8) \times 10^{2}$, and $(9.93 \pm 2.9) \times 10^{3} \mathrm{ng} / \mathrm{mL}$ for GM1, GM2, and GM3 respectively. In comparison, averaged monosialoganglioside levels in plasma samples from 12 heterozygous carriers were $(7.12 \pm 2.4) \times 10^{2},(2.38 \pm 1.0) \times 10^{2}$, and $(6.23 \pm 1.9) \times 10^{3} \mathrm{ng} / \mathrm{mL}$ for GM1, GM2, and GM3 respectively. This was slightly lower than the levels found in unaffected subjects, which is consistent with results reported in previous studies [15].

Interestingly, as a result of the enhanced sensitivity produced by the chemical derivatization of monosialogangliosides with DMTMM\&PAEA, we detected a significant amount of GM3 in the plasma of the GSD patients. As shown in Table 4, the level of GM3 from 12 of 14 GSD patients (2 patients remained immeasurable) averaged $(1.13 \pm 0.33) \times 10^{2} \mathrm{ng} / \mathrm{mL}$, while the level of GM2 remained undetectable. Although the amount of GM3 in the plasma of the GSD patients was small, accounting for approximately $1 \%$ of plasma abundance of GM3 in the unaffected adults, its presence was unequivocal. Since GM3 synthase is the key enzyme 
involving the initial stages of ganglioside biosynthesis, GSD would theoretically result in a complete absence of GM3 and all downstream biosynthetic derivatives in these patients [15, 32-33]. Given that GM3 was detected in the most affected patients, the question raised from our result is where the GM3 comes from. It is possible that the detected GM3 could be ingested from milk or food or generated from some unidentified ganglioside biosynthetic pathways in humans. The origin of the GM3 in the plasma from GSD patients remains elusive and is currently under investigation in our laboratory.

\section{Conclusion}

This paper presents the detailed development and validation of a sensitive LC/MS/MS method for the determination of monosialogangliosides GM1, GM2, and GM3 in human plasma via PAEA\&DMTMM-based chemical derivatization by using ${ }^{2} \mathrm{D}_{3}-\mathrm{GM} 1,{ }^{2} \mathrm{D}_{3}-\mathrm{GM} 2$, and ${ }^{2} \mathrm{D}_{3}-\mathrm{GM} 3$ as ISs. In brief, the standards and ISs were rapidly extracted from plasma using protein precipitation, purified through liquid-liquid extraction, and derivatized under optimized conditions prior to LC/MS/MS analysis. This method employed the UPLC system in gradient elution for chromatographic separation and Multiple Reaction Monitoring (MRM) for mass spectrometric detection. It has been successfully applied to the measurement of ganglioside levels in plasma samples from GSD patients, carriers, and normal human subjects. Regarding its high specificity, sensitivity, and throughput, this method could be applicable for therapeutic evaluation and clinical diagnosis of other ganglioside-related 
neurodegenerative disorders in the near future.

\section{Acknowledgements}

We thank the families for their patience and support. The study was supported in part by the Zverina Family Fund and Fonterra to DDC Clinic and the Dissertation Research Award from Cleveland State University to QH. The UPLC-MS/MS system used for this study was purchased by a grant from the Major Research Instrumentation Program (MRI) of the National Science Foundation (NSF) under grant number CHE-0923308. 


\section{References:}

[1] L. Svennerholm, Thegangliosides. Journal of lipid research 5 (1964) 145-55.

[2] R.K. Yu, Y. Nakatani, and M. Yanagisawa, The role of glycosphingolipid metabolism in the developing brain.Journal of Lipid Research (2009) S440-S445.

[3] R.K. Yu, Y. Tsai, T. Ariga, and M. Yanagisawa, Structures, biosynthesis, and functions of gangliosides-an overview. Journal of Oleo Science 60 (2011) 537-544.

[4] E.G. Bremer, J. Schlessinger, and S. Hakomori, Ganglioside-mediated modulation of cell growth. Specific effects of GM3 on tyrosine phosphorylation of the epidermal growth factor receptor. The Journal of biological chemistry 261 (1986) 2434-40.

[5] E.G. Bremer, and S. Hakomori, Gangliosides as receptor modulators. Advances in experimental medicine and biology 174 (1984) 381-94.

[6] E.G. Bremer, S. Hakomori, D.F. Bowen-Pope, E. Raines, and R. Ross, Ganglioside-mediated modulation of cell growth, growth factor binding, and receptor phosphorylation. The Journal of biological chemistry 259 (1984) 6818-25.

[7] T. Farooqui, T. Kelley, K.M. Coggeshall, A.A. Rampersaud, and A.J. Yates, GM1 inhibits early signaling events mediated by PDGF receptor in cultured human glioma cells. Anticancer research 19 (1999) 5007-13.

[8] A.J. Yates, H.E. Saqr, and B.J. Van, Ganglioside modulation of the PDGF receptor. A model for ganglioside functions. Journal of neuro-oncology 24 (1995) 65-73.

[9] M. Slevin, S. Kumar, X. He, and J. Gaffney, Physiological concentrations of gangliosides GM1, GM2 and GM3 differentially modify basic-fibroblast-growth-factor-induced mitogenesis and the associated signalling pathway in endothelial cells. International journal of cancer82 (1999) 412-23.

[10] T. Farooqui, and A.J. Yates, Effect of GM1 on TrkA dimerization. Annals of the New York Academy of Sciences 845 (1998) 407.

[11] A.M. Duchemin, N.H. Neff, and M. Hadjiconstantinou, Induction of Trk phosphorylation in rat brain by GM1 ganglioside.Annals of the New York Academy of Sciences 845 (1998) 406.

[12] T. Mutoh, A. Tokuda, T. Miyadai, M. Hamaguchi, and N. Fujiki, Ganglioside GM1 binds to the Trk protein and regulates receptor function. Proceedings of the National Academy of Sciences of the United States of America 92 (1995) 5087-91.

[13] A.J. Yates, and A. Rampersaud, Sphingolipids as receptor modulators.An overview. Annals of the New York Academy of Sciences 845 (1998) 57-71.

[14] Y. Liu, A. Wondimu, S. Yan, D. Bobb, and S. Ladisch, Tumor gangliosides accelerate murine tumor angiogenesis. Angiogenesis 17 (2014) 563-571.

[15] M.A. Simpson, H. Cross, C. Proukakis, D.A. Priestman, D.C.A. Neville, G. Reinkensmeier, H. Wang, M. Wiznitzer, K. Gurtz, A. Verganelaki, A. Pryde, M.A. Patton, R.A. Dwek, T.D. Butters, F.M. Platt, and A.H. Crosby, Infantile-onset symptomatic epilepsy syndrome caused by a homozygous loss-of-function mutation of GM3 synthase. Nature Genetics 36 (2004) 1225-1229. 
[16] F. Farukhi, C. Dakkouri, H. Wang, M. Wiztnitzer, and E.I. Traboulsi, Etiology of vision loss in ganglioside GM3 synthase deficiency. Ophthalmic Genetics 27 (2006) 89-91.

[17] H. Wang, A. Bright, B. Xinet al, Cutaneous dyspigmentation in patients with ganglioside GM3 synthase deficiency. Am J Med Genet161A (2013) 875-879.

[18] E.A. Fazzini, The effect of gangliosides on a neurotoxin (MPTP) induced model of Parkinson's Disease in mice., 1989, pp. 175 pp.

[19] P.E. Di, J. Fantini, H. Chahinian, M. Maresca, N. Taieb, and N. Yahi, Altered Ion Channel Formation by the Parkinson's-Disease-Linked E46K Mutant of $\alpha$-Synuclein Is Corrected by GM3 but Not by GM1 Gangliosides. Journal of Molecular Biology 397 (2010) 202-218.

[20] T. Ariga, M.P. McDonald, and R.K. Yu, Role of ganglioside metabolism in the pathogenesis of Alzheimer's disease-a review. Journal of Lipid Research 49 (2008) 1157-1175.

[21] F. Majer, L. Trnka, L. Vitek, M. Jirkovska, Z. Marecek, and F. Smid, Estrogen-induced cholestasis results in a dramatic increase of b-series gangliosides in the rat liver. Biomedical Chromatography 21 (2007) 446-450.

[22] B. Kniep, and P.F. Muehlradt, Immunochemical detection of glycosphingolipids on thin-layer chromatograms. Analytical Biochemistry 188 (1990) 5-8.

[23] E.M. Kaye, M.D. Ullman, E.H. Kolodny, W. Krivit, and J.C. Rischert, Possible use of CSF glycosphingolipids for the diagnosis and therapeutic monitoring of lysosomal storage diseases. Neurology 42 (1992) 2290-4.

[24] M.D. Ullman, and R.H. McCluer, Quantitative analysis of brain gangliosides by high performance liquid chromatography of their perbenzoyl derivatives.Journal of Lipid Research 26 (1985) 501-6.

[25] J. Kuei, G.R. Her, and V.N. Reinhold, Supercritical fluid chromatography of glycosphingolipids.Analytical Biochemistry 172 (1988) 228-34.

[26] D. Tsuji, Y. Higashine, K. Matsuoka, H. Sakuraba, and K. Itoh, Therapeutic evaluation of GM2 gangliosidoses by ELISA using anti-GM2 ganglioside antibodies. ClinicaChimicaActa 378 (2007) 38-41.

[27] J. Gu, C.J. Tifft, and S.J. Soldin, Simultaneous quantification of GM1 and GM2 gangliosides by isotope dilution tandem mass spectrometry. Clinical Biochemistry 41 (2008) 413-417.

[28] L.K. Soerensen, A liquid chromatography/tandem mass spectrometric approach for the determination of gangliosides GD3 and GM3 in bovine milk and infant formulae. Rapid Communications in Mass Spectrometry 20 (2006) 3625-3633.

[29] Q. Huang, X. Zhou, D. Liu, B. Xin, K. Cechner, H. Wang, and A. Zhou, A new liquid chromatography/tandem mass spectrometry method for quantification of gangliosides in human plasma. Analytical Biochemistry 455 (2014) 26-34.

[30] S. Endo, M. Morita, M. Ueno, T. Maeda, and T. Terabayashi, Fluorescent labeling of a carboxyl group of sialic acid for MALDI-MS analysis of sialyloligosaccharides and ganglioside. Biochemical and Biophysical Research Communications 378 (2009) 890-894.

[31] Food and Drug Administration. Guidance for Industry: Bioanalytical Method 
Validation. US Department of Health and Human Services, FDA, Center for Drug Evaluation and Research, Rockville, MD, 2001.

[32] K. Fragaki, S. Ait-El-Mkadem, A. Chaussenot, C. Gire, R. Mengual, L. Bonesso, M. Beneteau, J. Ricci, V. Desquiret-Dumas, V. Procaccio, A. Roetig, and V. Paquis-Flucklinger, Refractory epilepsy and mitochondrial dysfunction due to GM3 synthase deficiency. European Journal of Human Genetics 21 (2013) 528-534.

[33] L. Boccuto, K. Aoki, H. Flanagan-Steet, C. Chen, X. Fan, F. Bartel, M. Petukh, A. Pittman, R. Saul, A. Chaubey, E. Alexov, M. Tiemeyer, R. Steet, and C.E. Schwartz, A mutation in a ganglioside biosynthetic enzyme, ST3GAL5, results in salt \& pepper syndrome, a neurocutaneous disorder with altered glycolipid and glycoprotein glycosylation. Human Molecular Genetics 23 (2014) 418-433. 
Table 1

The quantification MRM transitions for the measured ganglioside species

\begin{tabular}{|c|c|c|c|c|c|c|c|}
\hline Species & $\begin{array}{c}\text { Collision } \\
\text { Energy } \\
\text { eV }\end{array}$ & Component & $\begin{array}{c}\text { MRM } \\
\text { Transition }\end{array}$ & Species & $\begin{array}{c}\text { Collision } \\
\text { Energy } \\
\text { eV }\end{array}$ & Component & $\begin{array}{c}\text { MRM } \\
\text { Transition }\end{array}$ \\
\hline \multirow{6}{*}{$\begin{array}{l}\text { PAEA- } \\
\text { GM1 }\end{array}$} & \multirow{6}{*}{39.9} & d18:1-14:0 & $805.6 / 411.2$ & \multirow{10}{*}{$\begin{array}{c}\text { PAEA- } \\
\text { GM3 }\end{array}$} & \multirow{10}{*}{33.0} & d18:1-14:0 & $622.9 / 411.2$ \\
\hline & & $\mathrm{d} 18: 1-16: 1$ & $818.6 / 411.2$ & & & d18:1-16:1 & $635.9 / 411.2$ \\
\hline & & d18:1-16:0 & $819.6 / 411.2$ & & & $\mathrm{~d} 18: 1-16: 0$ & $636.9 / 411.2$ \\
\hline & & d18:1-18:1 & $832.6 / 411.2$ & & & d18:1-18:1 & $649.9 / 411.2$ \\
\hline & & d18:1-18:0 & $833.6 / 411.2$ & & & d18:1-18:0 & $650.9 / 411.2$ \\
\hline & & $\mathrm{d} 18: 1-20: 0$ & $847.6 / 411.2$ & & & $\mathrm{~d} 18: 1-20: 0$ & $664.9 / 411.2$ \\
\hline \multirow{4}{*}{$\begin{array}{l}\text { PAEA- } \\
\text { GM2 }\end{array}$} & \multirow{4}{*}{34.9} & d18:1-16:0 & $738.7 / 411.2$ & & & $\mathrm{~d} 18: 1-21: 0$ & $671.9 / 411.2$ \\
\hline & & d18:1-18:1 & $751.7 / 411.2$ & & & $\mathrm{~d} 18: 1-22: 0$ & $678.9 / 411.2$ \\
\hline & & d18:1-18:0 & $752.7 / 411.2$ & & & d18:1-23:0 & $685.9 / 411.2$ \\
\hline & & d18:1-20:0 & 768.7/411.2 & & & d18:1-24:0 & $692.9 / 411.2$ \\
\hline
\end{tabular}

\section{Table 2}

Intra- and inter-assay precision and accuracy for the measurement of QC standards $(\mathrm{n}=5)$

\begin{tabular}{|c|c|c|c|c|c|c|c|c|}
\hline \multirow[b]{2}{*}{ Species } & \multirow[b]{2}{*}{ QC } & \multirow{2}{*}{$\begin{array}{c}\text { Spiked } \\
\text { Conc } \\
\text { (ng/ml) }\end{array}$} & \multicolumn{3}{|c|}{ Intra-assay } & \multicolumn{3}{|c|}{ Inter-assay } \\
\hline & & & $\begin{array}{c}\text { Mean } \pm S D \\
(\mathrm{ng} / \mathrm{ml})\end{array}$ & $\begin{array}{l}\text { Precision } \\
\text { (CV \%) }\end{array}$ & $\begin{array}{l}\text { Accuracy } \\
\text { (R.E.\%) }\end{array}$ & $\begin{array}{c}\text { Mean } \pm S D \\
(\mathbf{n g} / \mathrm{ml})\end{array}$ & $\begin{array}{l}\text { Precision } \\
(\mathrm{CV} \%)\end{array}$ & $\begin{array}{l}\text { Accuracy } \\
\text { (R.E. \%) }\end{array}$ \\
\hline \multirow{3}{*}{ GM1 } & Low & 25.0 & $27.7 \pm 0.90$ & 3.0 & 11 & $27.3 \pm 1.7$ & 6.0 & 9.0 \\
\hline & Mid & $2.50 \times 10^{2}$ & $\begin{array}{c}(2.63 \pm 0.18) \\
\times 10^{2}\end{array}$ & 7.0 & 6.0 & $\begin{array}{c}(2.74 \pm 0.15) \\
\times 10^{2}\end{array}$ & 5.0 & 10 \\
\hline & High & $1.60 \times 10^{3}$ & $\begin{array}{c}(1.43 \pm 0.13) \\
\times 10^{3}\end{array}$ & 9.0 & -11 & $\begin{array}{c}(1.58 \pm 0.040) \\
\times 10^{3}\end{array}$ & 3.0 & -1.0 \\
\hline \multirow{3}{*}{ GM2 } & Low & 25.0 & $23.4 \pm 1.9$ & 8.0 & -6.0 & $25.0 \pm 0.60$ & 2.0 & 0 \\
\hline & Mid & $2.50 \times 10^{2}$ & $\begin{array}{c}(2.35 \pm 0.099) \\
\times 10^{2}\end{array}$ & 4.0 & -6.0 & $\begin{array}{c}(2.42 \pm 0.081) \\
\times 10^{2}\end{array}$ & 3.0 & -3.0 \\
\hline & High & $1.60 \times 10^{3}$ & $\begin{array}{c}(1.62 \pm 0.040) \\
\times 10^{3}\end{array}$ & 2.0 & 1.0 & $\begin{array}{c}(1.67 \pm 0.11) \\
\times 10^{3}\end{array}$ & 7.0 & 4.0 \\
\hline \multirow{3}{*}{ GM3 } & Low & $2.00 \times 10^{2}$ & $\begin{array}{c}(2.09 \pm 0.14) \\
\times 10^{2}\end{array}$ & 7.0 & 5.0 & $\begin{array}{c}(2.11 \pm 0.083) \\
\times 10^{2}\end{array}$ & 4.0 & 5.0 \\
\hline & Mid & $2.00 \times 10^{3}$ & $\begin{array}{c}(2.06 \pm 0.080) \\
\times 10^{3}\end{array}$ & 4.0 & 3.0 & $\begin{array}{c}(2.06 \pm 0.060) \\
\times 10^{3}\end{array}$ & 3.0 & 3.0 \\
\hline & High & $1.28 \times 10^{4}$ & $\begin{array}{c}(1.26 \pm 0.050) \\
\times 10^{4}\end{array}$ & 4.0 & -2.0 & $\begin{array}{c}(1.26 \pm 0.060) \\
\times 10^{4}\end{array}$ & 5.0 & -3.0 \\
\hline
\end{tabular}


Table 3

The stability and extraction recovery of PAEA-monosialogangliosidesfrom plasma samples at QC concentrations $(n=5)$

\begin{tabular}{|c|c|c|c|c|c|c|}
\hline \multirow[b]{2}{*}{ Species } & \multirow[b]{2}{*}{ QC } & \multirow{2}{*}{$\begin{array}{c}\text { Spiked } \\
\text { Concentration } \\
(\mathbf{n g} / \mathbf{m l})\end{array}$} & \multicolumn{2}{|c|}{ Autosampler Stability } & \multicolumn{2}{|c|}{ Extraction Recovery } \\
\hline & & & $\begin{array}{c}\text { Mean } \pm \text { SD } \\
(\%)\end{array}$ & $\begin{array}{l}\mathrm{CV} \\
(\%)\end{array}$ & $\begin{array}{c}\text { Mean } \pm \text { SD } \\
(\%)\end{array}$ & $\begin{array}{l}\text { CV } \\
(\%)\end{array}$ \\
\hline \multirow{3}{*}{ GM1 } & Low & 25.0 & $103 \pm 7.0$ & 7.0 & $94.0 \pm 7.0$ & 8.0 \\
\hline & Mid & $2.50 \times 10^{2}$ & $101 \pm 8.0$ & 8.0 & $84.0 \pm 3.0$ & 4.0 \\
\hline & High & $1.60 \times 10^{3}$ & $102 \pm 3.0$ & 3.0 & $80.0 \pm 2.0$ & 3.0 \\
\hline \multirow{3}{*}{ GM2 } & Low & 25.0 & $104 \pm 13$ & 12 & $84.0 \pm 3.0$ & 4.0 \\
\hline & Mid & $2.50 \times 10^{2}$ & $107 \pm 3.0$ & 3.0 & $83.0 \pm 2.0$ & 3.0 \\
\hline & High & $1.60 \times 10^{3}$ & $100 \pm 3.0$ & 3.0 & $81.0 \pm 6.0$ & 7.0 \\
\hline \multirow{3}{*}{ GM3 } & Low & $2.00 \times 10^{2}$ & $100 \pm 10$ & 10 & $102 \pm 4.0$ & 4.0 \\
\hline & Mid & $2.00 \times 10^{3}$ & $103 \pm 5.0$ & 5.0 & $83.0 \pm 8.0$ & 10 \\
\hline & High & $1.28 \times 10^{4}$ & $100 \pm 4.0$ & 4.0 & $80.0 \pm 6.0$ & 8.0 \\
\hline
\end{tabular}

\section{Table 4}

Determination of monosialoganglioside levels in plasma samples from different specimens.

\begin{tabular}{|c|c|c|c|c|}
\hline Subject & Total & $\begin{array}{c}\text { GM1 } \\
\text { Mean } \pm \text { SD } \\
(\mathbf{n g} / \mathbf{m L})\end{array}$ & $\begin{array}{c}\text { GM2 } \\
\text { Mean } \pm \text { SD } \\
(\mathbf{n g} / \mathbf{m L})\end{array}$ & $\begin{array}{c}\text { GM3 } \\
\text { Mean } \pm \text { SD } \\
(\mathbf{n g} / \mathbf{m L})\end{array}$ \\
\hline Normal Subject & 31 & $(1.35 \pm 0.39) \times 10^{3}$ & $(4.71 \pm 1.8) \times 10^{2}$ & $(9.93 \pm 2.9) \times 10^{3}$ \\
\hline GSD Carrier & 12 & $(7.12 \pm 2.4) \times 10^{2}$ & $(2.38 \pm 1.0) \times 10^{2}$ & $(6.23 \pm 1.9) \times 10^{3}$ \\
\hline GSD Patient & 14 & $(9.81 \pm 3.9) \times 10^{2}$ & $\mathrm{NM}$ & $(1.13 \pm 0.33) \times 10^{2}$ \\
\hline
\end{tabular}

Note:

1. NM-Not Measurable

2. Plasma levels of GM2\&GM3 below LLOQ were determined by using $20 \mu \mathrm{L}$ plasma samples in conjunction with $10 \mu \mathrm{L}$ calibrator as described in Section 2.4, Sample Preparation. 


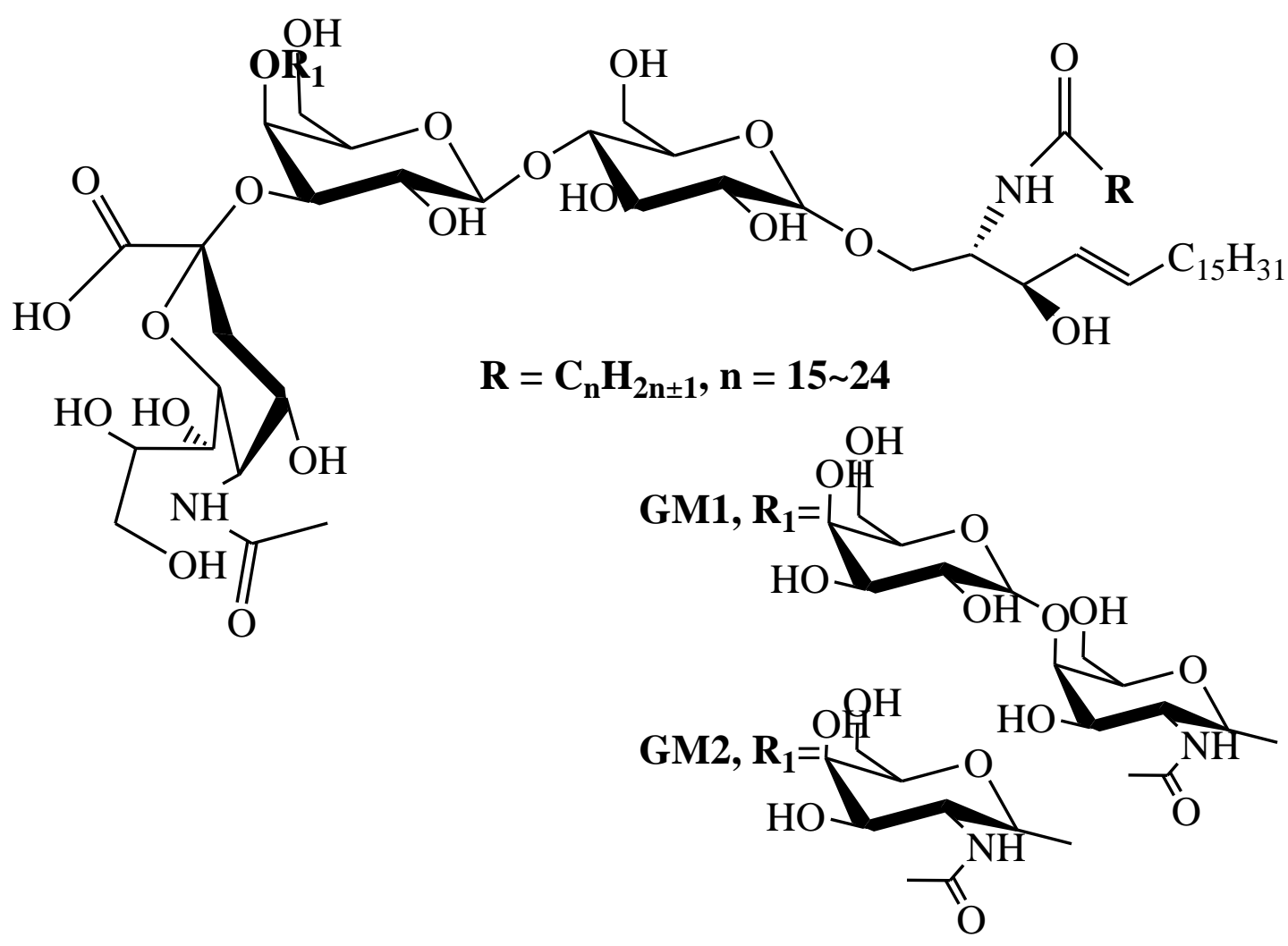

GM3, $\mathbf{R}_{\mathbf{1}}=\mathbf{H}$

Fig.1. Chemical structures of monosialogangliosides. 

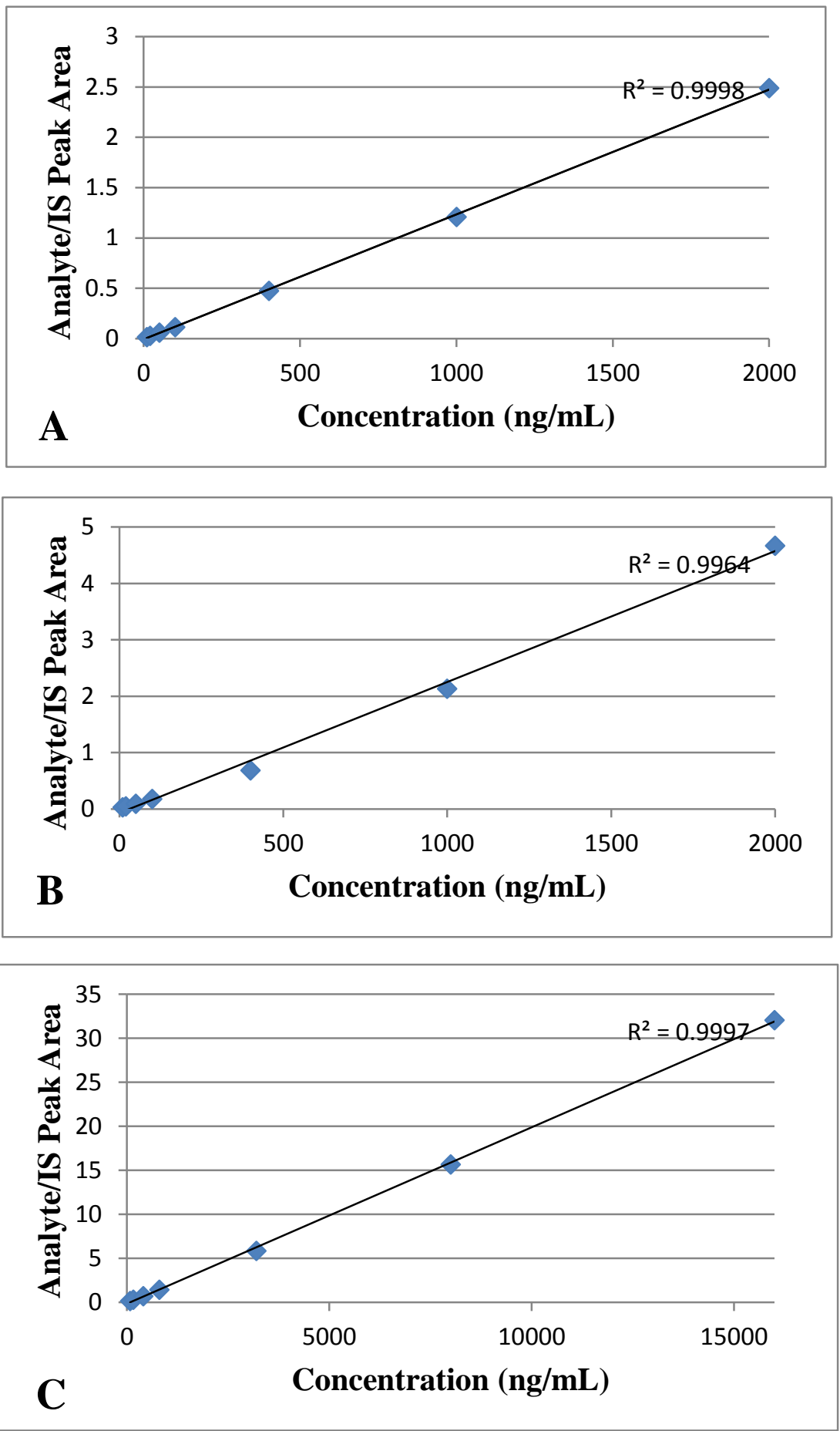

Fig.2. Calibration curves for GM1 (A), GM2 (B), and GM3 (C). 

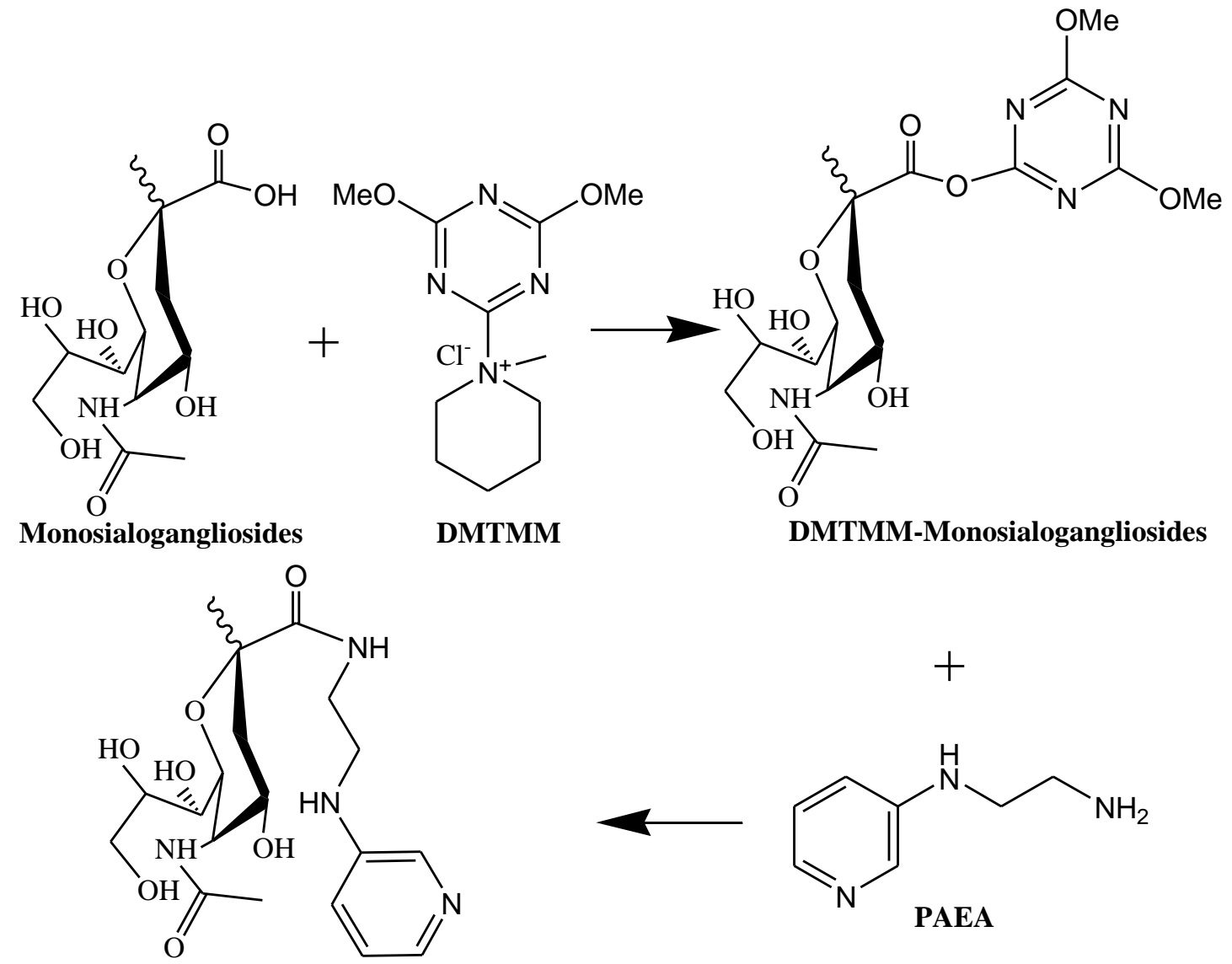

PAEA-Monosialogangliosides

Fig.3. Elaborated Reaction Mechanism for PAEA\&DMTMM-based Derivatization 


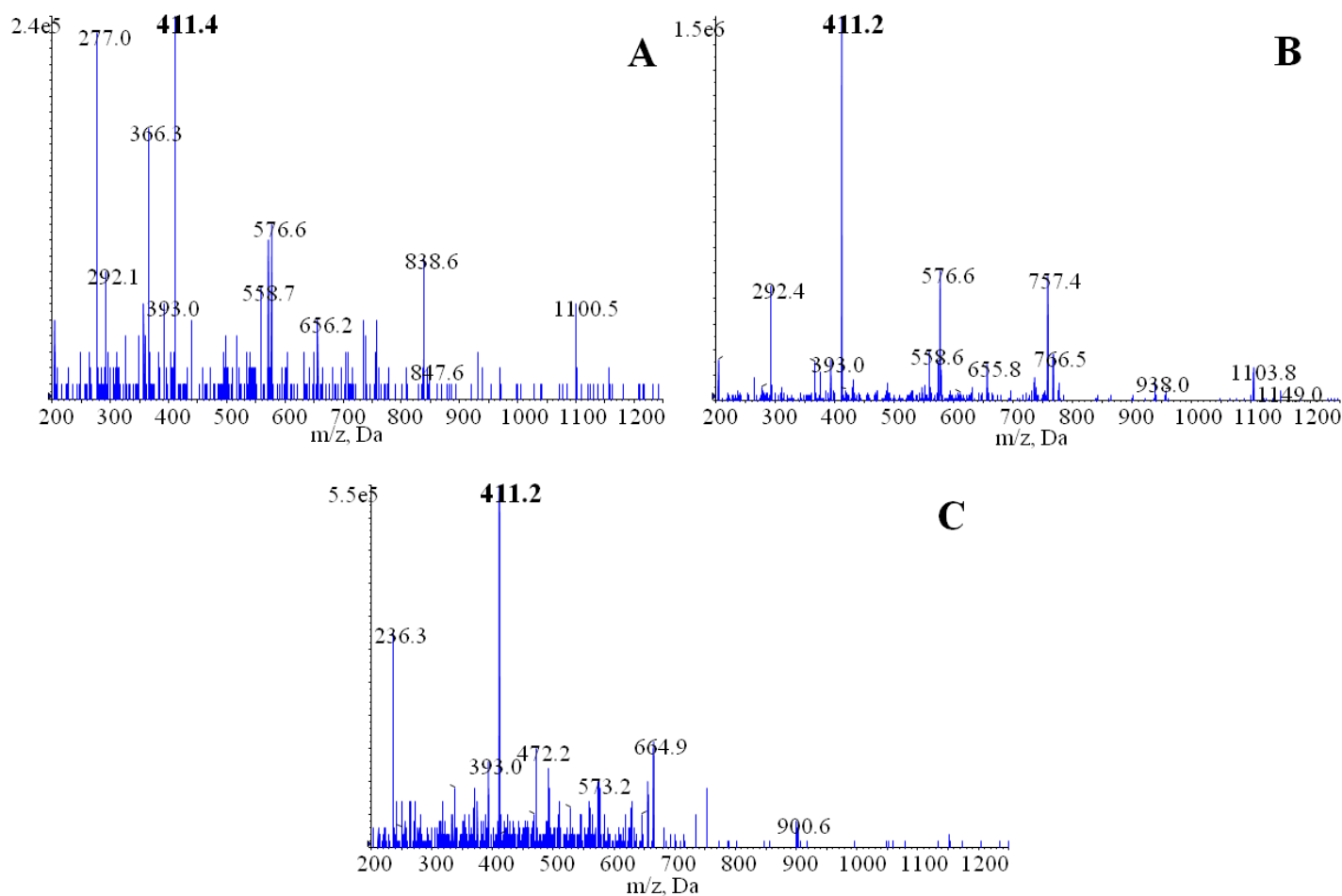

Fig.4. The product ion (MS/MS) spectra for d18:1-20:0 components of derivatized GM1 (A), GM2 (B), and GM3 (C). 


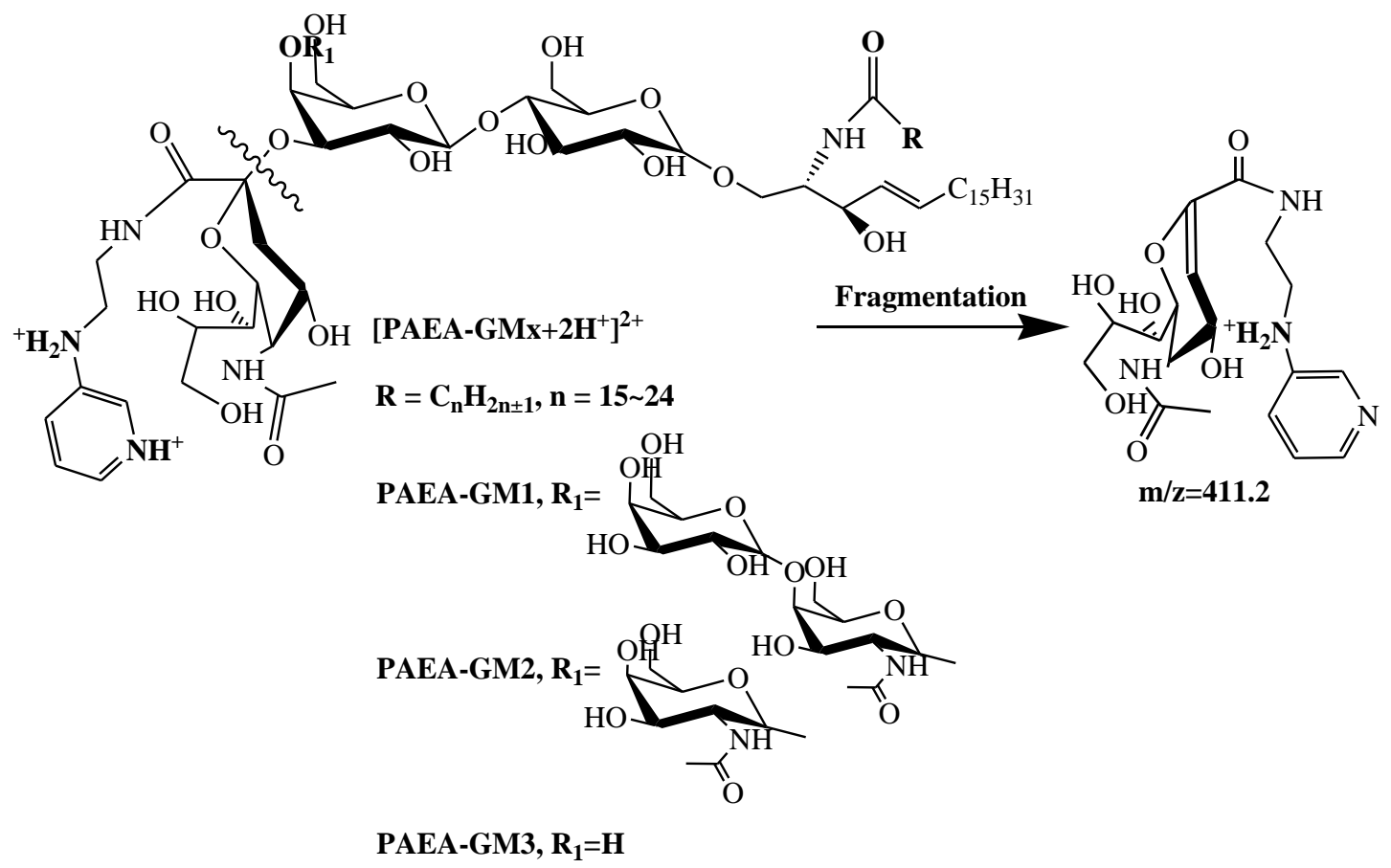

Fig.5. Proposed fragmentation mechanism for derivatized GM1, GM2, and GM3 


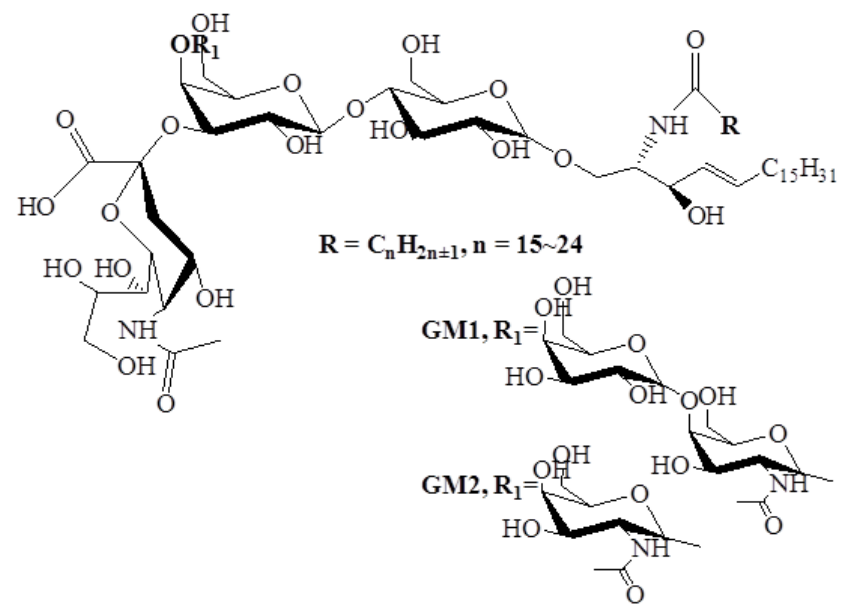

GM3, $\mathrm{R}_{1}=\mathrm{H}$

Fig.1. Chemical structures of monosialogangliosides. 

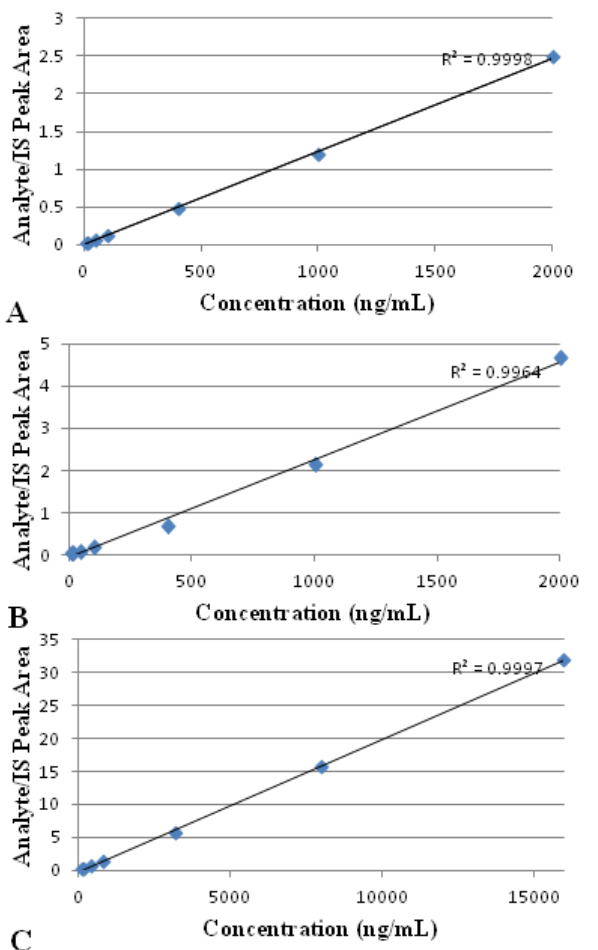

Fig.2. Calibration curves for GM1 (A), GM2 (B), and GM3 (C) 


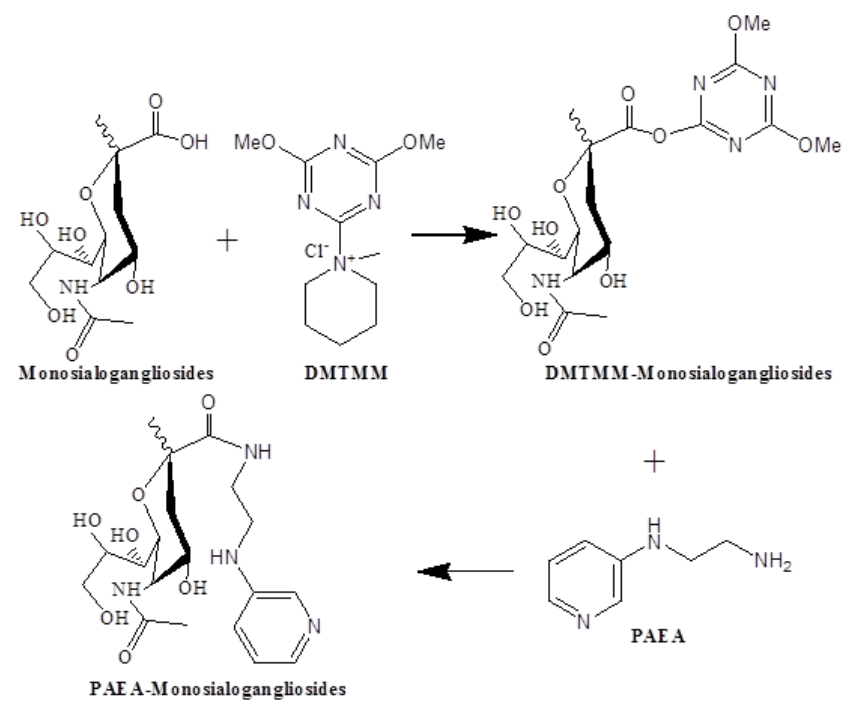

Fig.3. Elaborated Reaction Mechanism for PAEA \&DMTMM-based Derivatization 


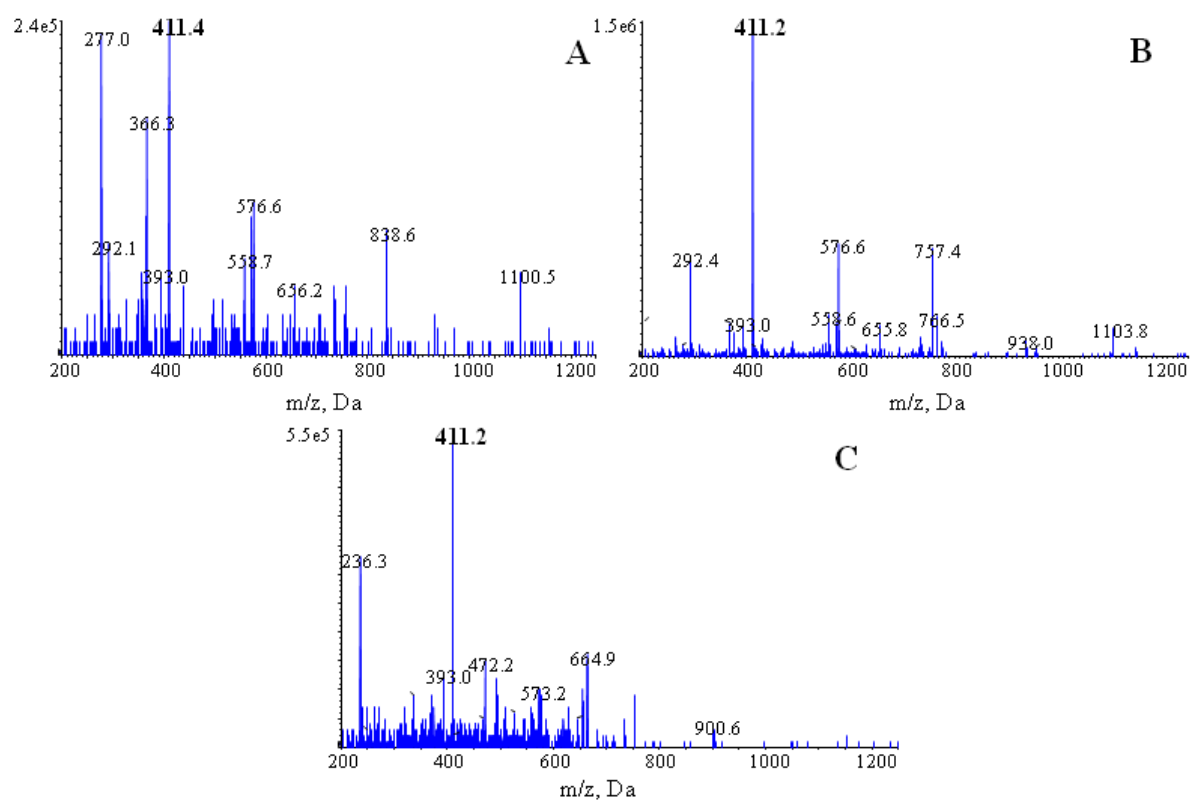

Fig.4. The product ion (MS/MS) spectra for d18:1-20:0 components of derivatized GM1 (A), GM2 (B), and GM3 (C) 


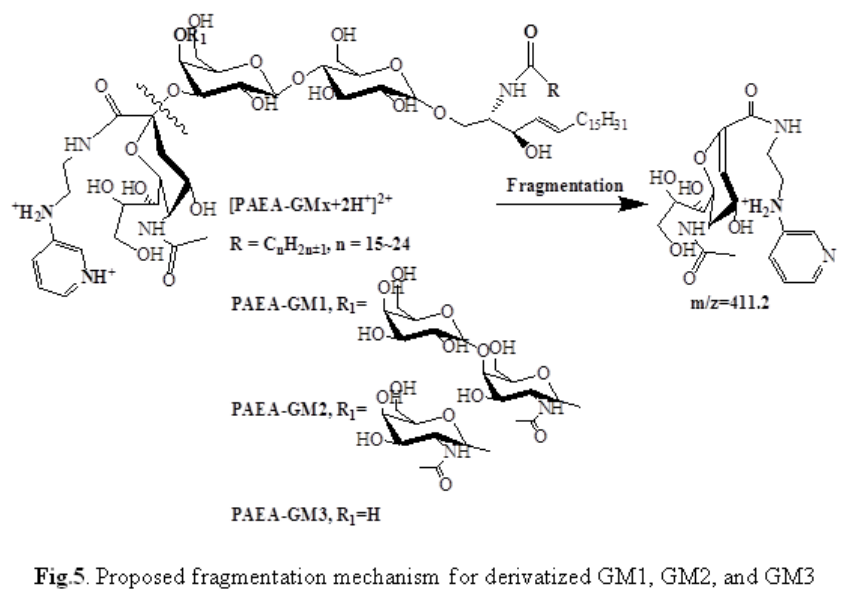

34 


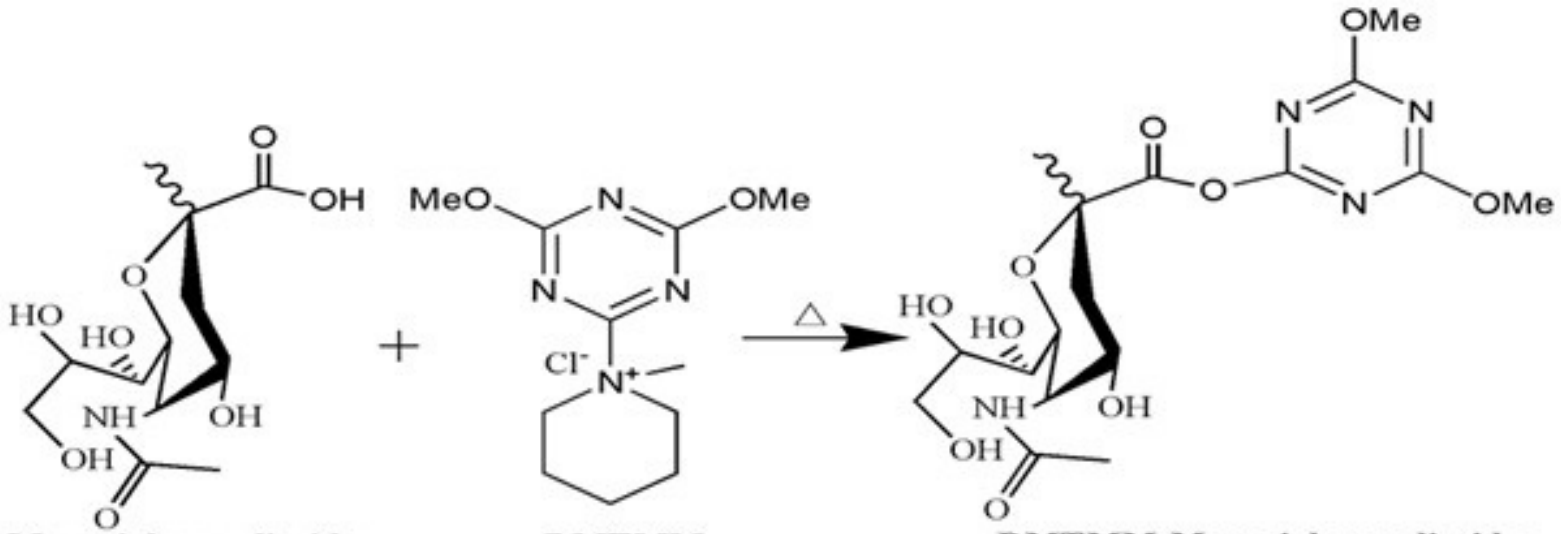

\section{Monosialogangliosides}

DMTMM

DMTMM-Monosialogangliosides
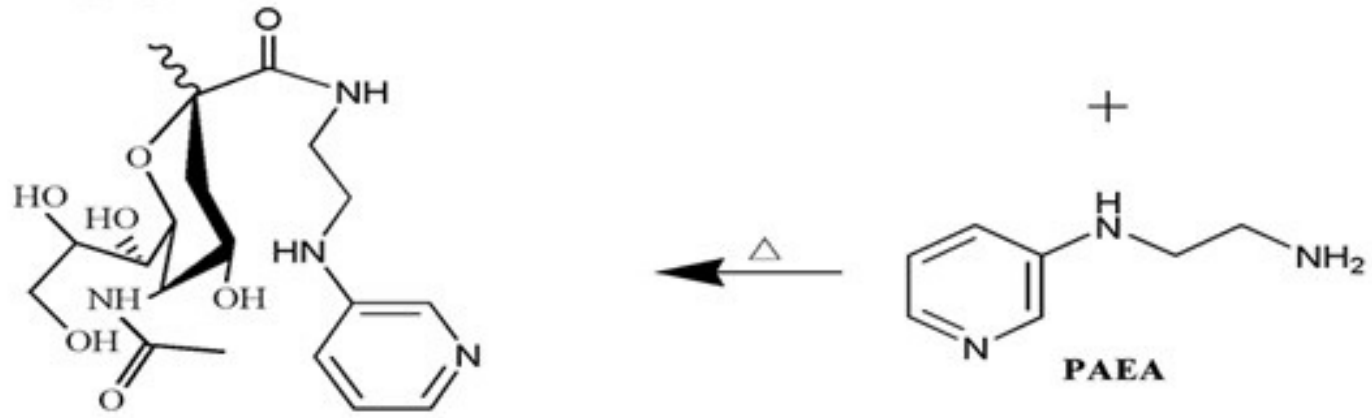

PAEA-Monosialogangliosides 